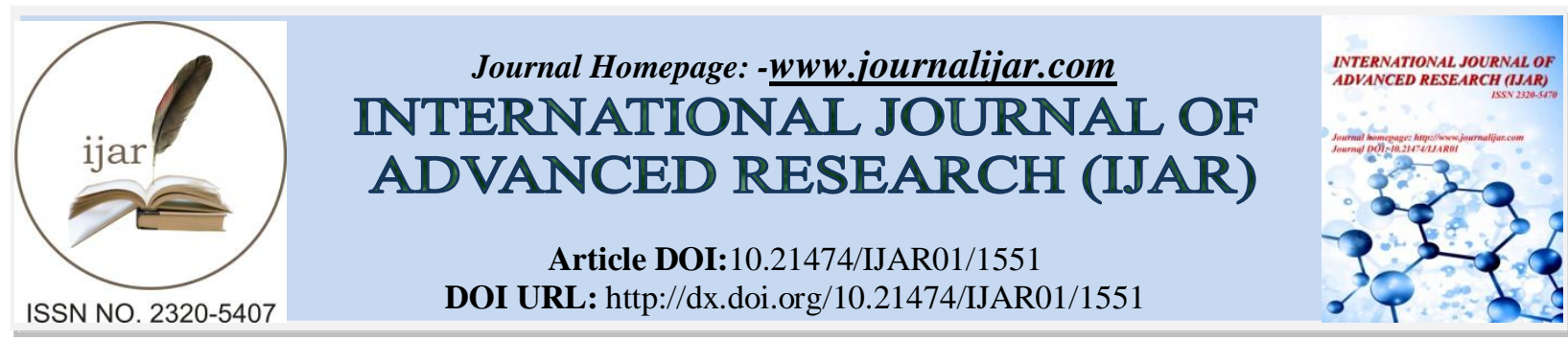

RESEARCH ARTICLE

\title{
VULNERABILITY ANALYSIS OF THE COASTAL LIVELIHOODS IN BANGLADESH:DOES VULNERABILITY CONSTRUCT THROUGH EXOGENOUS DRIVERS OR DUE TO ENDOGENOUS REALITIES?
}

Atiq Kainan Ahmed ${ }^{1}$ and Afsana Yasmeen ${ }^{2}$.

1. Asian Disaster Preparedness Center (ADPC), Thailand.

2. Integrated Coastal Zone Management Program (ICZMP), Bangladesh

\section{Manuscript Info}

(...........................

Manuscript History

Received: 15 July 2016

Final Accepted: 22 August 2016

Published: September 2016

Key words:-

Vulnerability, Livelihoods, Integrated

Coastal Zone Management (ICZM),

Social-ecological system, Resilience,

Climate Change Adaptation.

\section{Abstract}

The nature of vulnerability perceived by various livelihood groups residing in the coastal zone of Bangladesh relates to many domains demonstrating a high degree of exposure to climate change induced natural disasters, social ecological systems, and prevailing risk factors. An empirical social-ecological assessment was conducted to understand the prevailing factors relating to the livelihoods-based vulnerability and adaptation issues in the coastal districts of Bangladesh. The vulnerability assessment focused on the major coastal livelihoods such as small farmers, artisanal fishers, urban wage laborers and rural wage laborers and found that vulnerabilities vary in nature and intensity across these livelihood groups. The assessment findings and recommendations calls for specific policies addressing the diversity of vulnerabilities experienced by these large groups in the coastal zone. Results and analysis indicated that across these major coastal livelihood groups, vulnerabilities are rather perceived to be the function of exogenous factors but due to endogenous characteristics. A major conclusion emerged from the assessment is that the vulnerabilities for each major livelihood groups varies both in nature and in intensity in the coast. The overriding chronic poverty situation on top of these have remained as a common barrier to build any strong resilience against exogenous forms of vulnerabilities. This set of finding calls for a policy implication that would compose of issues of reduction of livelihood group specific unique patterns of vulnerability as well as building multi-layered resilience against climate induced natural disasters in general. This set of findings helped the Integrated Coastal Zone Management Program (ICZMP) to better devise the Coastal Development Strategy (CDS) in the country and subsequently consolidation of the National strategies relating to various sectoral aspects of climate change adaptationfor the coastal zone at a later stage.

Copy Right, IJAR, 2016,. All rights reserved. 


\section{Introduction:-}

Bangladesh as a low lying deltaic country is one of the most climate vulnerable countries in the world and will become even more so as a result of climate change. Floods, tropicalcyclones, storm surges, sea level rise, salinity and other hazards are anticipated tobecome more frequent and severe for the coastal areas of Bangladesh (MOEF, 2008). The coastal zone of Bangladesh has an area of $42,154 \mathrm{sq} . \mathrm{km}$ covering nineteen districts with a total population of 31.8 million. The eastern part of the coastal zone consists of a narrow strip of relatively stable land mass with a long unbroken sea beach. The middle part of the coastal zone is formed mainly by the Meghna estuary. The land mass is dynamic with active accretion and erosion process. There are large islands in this region such as Sandwip, Hatiya and Bhola. The western part of the coastal zone is part of Ganges tidal plain. The southern part of this region is covered with mangrove forest, the Sundarbans. Second and third largest cities of the country, namely Chittagong and Khulna are situated in the coastal zone. These two cities are also major industrial hubs. There are two seaports, Chittagong and Mongla. Agricultural farming, artisanal fishing, shrimp and salt farming are important activities in the rural areas. Large number of people of western region also depends on various resources of the Sundarbans. There is widespread poverty, both income and human, in the coastal zone. Livelihoods in the coastal zone are vulnerable to a variety of shocks (e.g. tropical cyclone), trends (e.g. climate change) and seasonality (e.g. salinity). Understanding what different groups of people are vulnerable to and how they respond to various vagaries is crucial to the formulation of policies, programmes and projects to reduce the level of risk faced by poor people and enhancing their resilience and capacity to adapt tothese shocks and stresses in a proactive manner.

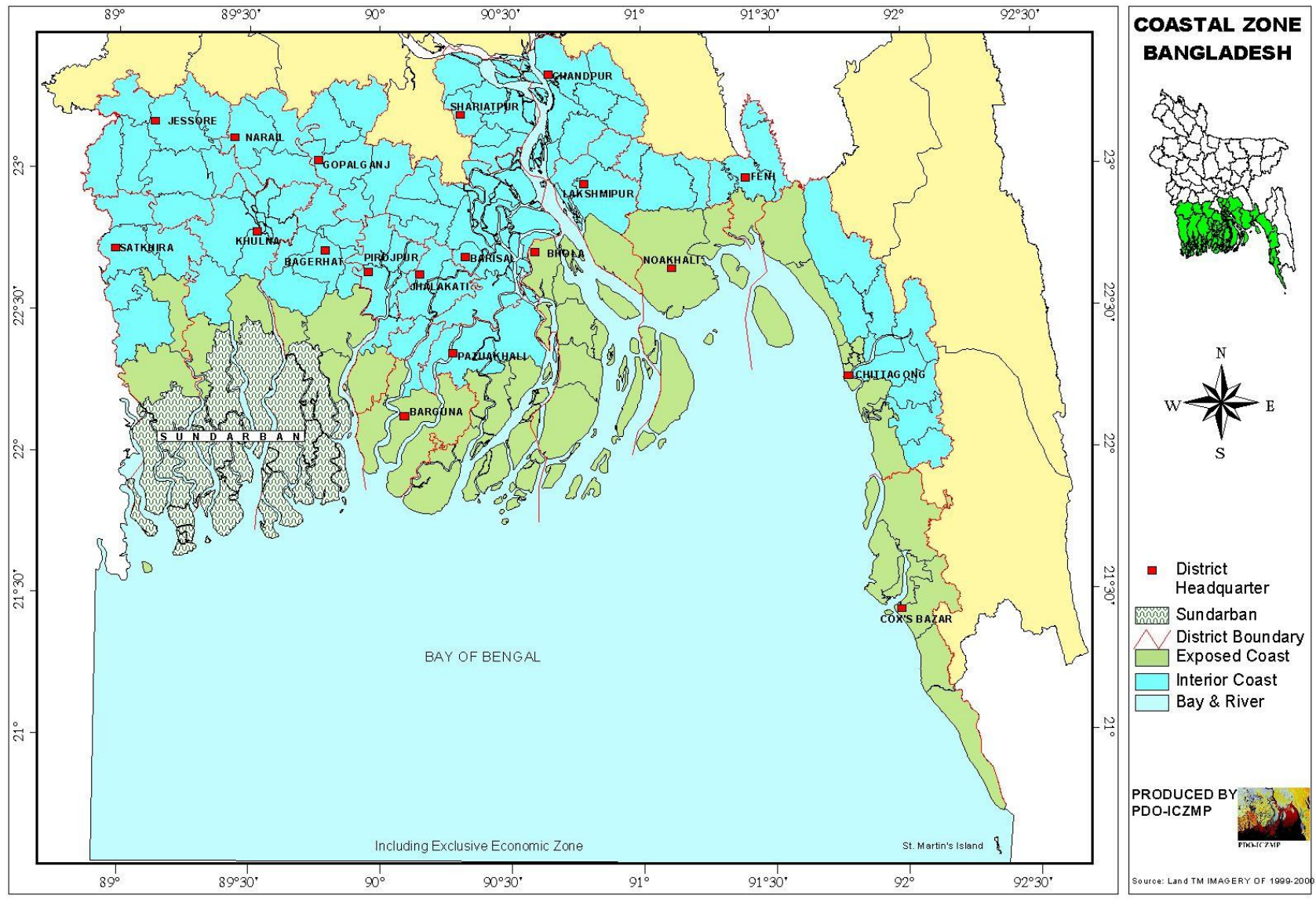

Figure 1:- The coastal zone of Bangladesh comprising of 19 (exposed and interior) districts (Source: ICZMP).

\section{Approach and Methodology:-}

The methodology for this assessment is built on a foundation of a gradually developed multi-stageapproach in three different phases. Before starting the assessment of the vulnerabilities and adaptation of coastal livelihoods it was important to underpin the understanding of the concept of vulnerability itself. The study methodology, hence,started with an extensive review of related literature in the Phase-I of the study. This entailed an analytical review of 
existing information sources (published and gray literature both) which provided a preliminary understanding of: a) the vulnerability context of coastal communities, defined as 'shocks', 'trends' and 'seasonality', as well as the adaptive strategies and capacities enacted to prepare for, prevent or respond to shocks; b) the principal vulnerable groups or groups of people facing specific types of risks; and c) the vulnerable zones with respect to trends, shocks and seasonality patterns. Simultaneously, a series of other existing datasets (agricultural census, socio-economic surveys, etc.) as well as spatial datasets (e.g. disaster prone maps, salinity intrusion map, sea level rise map) were analyzed to construct a comprehensive picture of vulnerability in coastal zones. This process allowed the identification of: a) areas (disaggregated at district and upazila level) vulnerable to specific types of events (shocks, trends, seasonality); b) the share of each livelihood group per district; and c)coping strategies and mechanisms enacted by different livelihood groups in different coastal areas, including successes, failures, best practices and lessons learned.

In the Phase-II of the study a series of Focus Consultation Sessions (FCS) with key stakeholders were carried out in each of the 19 coastal districts of Bangladesh. Each consultation group approximately comprised up to 18-25 participants representing different livelihood groups, local government agencies, representatives of NGOs working in a given district, managers of current projects, and others established on a case by case basis. The selection was made jointly with local NGO forums at district level and a network of people knowledgeable about each specific coastal district. The FCSs with the key stakeholders in the field aimed to elicit important and often tacit knowledge information vested in local institutions and key resources people, while on the other hand it aimed at involving subnational level stakeholders from the very beginning in the process of identifying vulnerabilities and the coping strategies existing in the coastal zone of Bangladesh to facilitate the development strategies to be outlined by the Government. At the end of the consultation process, a complete matrix highlighting all types of vulnerabilities to which specific types of livelihood groups are subjected to, as well as the adaptation strategies available to them, including best practices and lessons learned, was made. This information was geo-referenced and triangulated with existing maps to provide a comprehensive picture of vulnerability across the spectrum of each livelihood group and in each district.

At the final stage of the assessment, Phase-III four regional meetings were held in the coastal zones of Bangladesh to present and validate preliminary findings. A limited number of representatives from each of the concerned districts were invited. Invitations were sent to the same people who participated in the first round of consultation for consistency purposes. The major aim of this phase was to verify the consultation/group level findings which were acquired in earlier phases of the study and from household level in the communities residing in different parts of the coastal zone and at the same time get a greater insight into the unique contexts through some case studies focusing on various themes identifying unique and respective issues, type of communities and geo-graphical areas.

\section{Underpinning the understanding towards 'Vulnerability':-}

A large body of literature has been produced on the subject of vulnerability from the late 1980s onwards in the development arena. This stems primarily from the work on entitlements initiated by Amartya Sen (1981) who sparked the discussion on the erosion of assets and the processes that render people subject to negative outcomes as a result of exposure to risk factors. Robert Chambers (1989) elaborated on Sen's ideas and formulated a definition of vulnerability which has ever since changed the terms of discourse in the debate about poverty and food security. For Chambers "vulnerability has two sides: an external side of risks, shocks, and stress to which an individual or household is subject: and an internal side which is defenselessness" (Chambers 1989).

As Dilley and Boudreau (2001) argue, there are major discrepancies as to the definition of vulnerability. This is primarily a function of the different disciplines from which the debate about vulnerability emerged. In this debate the concept of vulnerability assumed a multiplicity of meanings and is utilized as an equivalent linguistic sign despite its diverse connotations. Dilley and Boudreau (2001) evidence two major and competing definitions of vulnerability emerging from the food security literature on the one hand and the disaster management discourse on the other. In the debate about food security vulnerability is defined in relation to an outcome such as hunger, food insecurity or famine. This precludes an identification of causal factors contributing to those outcomes, because no emphasis is put on exogenous events that make populations susceptible to a deteriorating situation. Conversely, in the disaster management literature, vulnerability is used to identify those characteristics of the population (endogenous) that make them susceptible to experiencing damage when exposed to shocks. For Dilley and Boudreau this latter theoretical conceptualization of risk and vulnerability offers a better roadmap to its use in operational settings. 
In addition to the food security and disaster management bodies of literature, vulnerability is becoming increasingly important in the economists' debates about poverty. Most authors argue for the need to distinguish conceptually between the notions of poverty and vulnerability. This is based on idea that poverty - in the manner it is measured is a static concept, while vulnerability is by contrast a more dynamic one, capturing processes of change (Moser 1998). However, economists widely acknowledge that people move in and out of poverty all the time, and thus poverty itself needs to be seen as a more fluid condition, fluctuating in intensity and nature over time. Though a proportion of poor people remain poor year in and year out, longitudinal studies in developed countries have shown that most people fall below the poverty line only temporarily, mostly in connection with a temporary shock such as illness or the loss of employment. The situation often reverts in a few years. The opposite condition, however, also holds true - i.e. poor people who manage to come out of poverty do so only temporarily to fall back below the poverty line within a few years. A better understanding of these dynamics bears an enormous significance for the design of effective poverty reduction policies and actions. Targeting poor people on the basis of their current status, in fact, may lead to wrong actions.

An understanding of poverty as flexible and dynamic in nature is also supported by the work of Baulch and Hoddinot (2000) who reviewed data from 10 developing countries. The authors concluded that the number of households remaining below the poverty line for one or two years was almost always larger than the number of households remaining below the poverty line for longer periods of time. Thus vulnerability seems to be an intrinsic characteristic of poverty rather than an external factor contributing to it. Whereas it is clear that poverty and vulnerability are not the same thing, defining rigid conceptual boundaries risks circularity. If vulnerability is the risk of people falling into poverty, and if that risk is a function of the level of assets (e.g. current status that may or may not be poverty), then vulnerability is a function of poverty and vice versa in cases where people's entitlements and capacities are already low (endogenous factors). In other cases vulnerability may be a function of endogenous and exogenous factors, or exogenous factors only, the consequences of which are going to erode the asset basis of a given household or individual and thereby reduce capacity to manage, mitigate or respond to risk.

The conceptual crossroad between poverty and vulnerability is indeed blurry. For Chambers "vulnerability, more than poverty, is linked with net assets. Poverty, in the sense of low income can be reduced by borrowing and investing: but such debt makes households more vulnerable. Poor people, in their horror of debt, appear more aware than professionals of the trade-offs between poverty and vulnerability." There is a tendency to define poverty as the "lack of" something, be it productive assets, education, or purchasing power. Lack of assets is an intrinsic aspect of vulnerability and trying to define cut and dry conceptual boundaries between poverty and vulnerability may lead to confusion. Although Chambers (1989) in his seminal piece on vulnerability warned against the potential dangers in failing to distinguish between poverty and vulnerability, the divide is more complex than it appears. What can be seen as poverty e.g. as the result of a series of dynamics today - including past vulnerability - is indeed making people vulnerable to a whole series of events and dynamics for the future. Moser (1998) argues that the more assets people have, the less vulnerable they are, and the greater the erosion of people's assets, the greater their insecurity. This vision of vulnerability as being an integral part of poverty is supported by McCulloch and Calandrino (2003) in their analysis of chronic poverty in rural China. They adopt a new measure of chronic poverty defined as the vulnerability to being poor instead of considering it as a static measure of consumption. They argue that households can be very vulnerable to falling into poverty even when their average consumption is not marginally above the poverty line, and conclude that the determinants of low consumption and high vulnerability are in large part coterminus.

Therefore, it is more productive to think as vulnerability as an aspect of poverty rather than an external element to it. As Action Aid puts it in one of its documents: "all poor are vulnerable and most vulnerable people are poor". Chambers (1989) subscribes to this rationale by pointing out that the poor are often the least resilient to absorb external shocks and risks. As the poorest are also those who have the fewest immediate entitlements and assets, they are often the most vulnerable (Swift 1989).

These observations point to the fact that thinking sequentially or in teleological terms - e.g. when vulnerability precedes par force poverty or any other outcome such as food insecurity - may be misleading. Poverty and vulnerability interrelate and mutually generate or reinforce each other, and though a reduction in poverty or vulnerability may lead to an improvement in the other variable, the reverse may not be true necessarily. Also, over time the degree of exposure to a shock (say drought) may remain constant, but the degree of total vulnerability of an 
individual or a household may actually increase with the depletion of asset bases that are utilized over time to cope with that very shock element (Devereux 2001). Vulnerability is therefore a function of immediate entitlement failures, and the extent to which existing buffers have been exhausted. These latter are in turn a function of the intensity, duration and frequency of past risk exposure (Maxwell and Smith 1992).

As argued above, vulnerability varies over time, between and within households, and co-varies with age, gender, social status, and physical conditions among other variables. There is also a geographical dimension to vulnerability, though not all household in the same area are equally vulnerable. Their degree of vulnerability is primarily a function of their differential coping capacity. Devereux (2001) identifies also a public element in vulnerability - e.g. the existence and functioning of social protection schemes. These, however should not be simply reactive but rather preventive. Reactive measures, in fact, can only affect coping strategies but not reduce the risk faced by individuals or households. Finally, vulnerability can be also seen as a degree of exposure and resilience (Frankenberger and Maxwell 1992, Devereux 2001). This model introduces the concept of "coping" capacity, mechanism and strategies, which occupies a pivotal role in the discussion about vulnerability.

The study adopted the term 'vulnerability as a twofold concept' which entails the likelihood of events that may result in a series of negative livelihood outcomes, as well as the coping mechanisms that people enact to face such risk events. While the former are normally exogenous factors, the latter are a function of endogenous characteristics of the individual, the household or the community facing external factors. Exogenous factors may have the nature of: a) trends (e.g. depletion of natural resources from which the population makes its living, food price inflation), b) shocks (e.g. natural disasters, conflicts), and c) seasonality (e.g. seasonal employment opportunities, seasonal incidence of disease). Endogenous factors comprise the characteristics of people, the general conditions in which they live, the access they have to local resources, and their capacity to prevent, prepare for or respond to a given shock.

\section{Analysis of vulnerabilities of the coastal livelihood groups:-}

During the initial stage of the study the actual identification and distribution of the population of the major livelihood groups are carried out from the secondary sources. Occupational data were collected from available national Population Census (BBS: 1992) and Agricultural Census 1996 (BBS: 1999) data. Secondary sources suggested that the four livelihood groups -- small farmer, artisanal fisher, rural wage labour, and urban wage labour - residing in the coastal districts of Bangladesh can be identified as the major livelihood groups. Together the population of these four major livelihood groups comprise approximately $73 \%$ of the total population of the coast. The study considered these four major livelihood groups for vulnerability analysis and further profiling. A total of 156 vulnerability factors were obtained through the fieldwork. For analytical purposes, these vulnerability factors were grouped into 13 composite variables. These composite variables, in turn, can be clustered along four major thematic areas shown in the Table below.

Table 1:- Vulnerability domains emerged in the study.

\begin{tabular}{|l|l|l|l|}
\hline Environmental/ physical & Economic & Social & Governance/ institutional \\
\hline Water & Employment & Social issues & Health \& education \\
$\begin{array}{l}\text { Disasters (climate } \\
\text { changed induced) }\end{array}$ & Productive activities & Women's conditions & Infrastructure \& services \\
Environment & Household assets & Illegality & Governance \\
\hline
\end{tabular}

From the vulnerability analysis it emerged that these thirteen vulnerability domains (and also combination of domains) are affecting livelihood groups differently.

Environmental issues are more prominent for livelihood groups involved in primary production activities. The composite variable "environment" summarizes a series of observations about the current state of natural resources and processes affecting them. In both cases, these observations are perceived to be directly linked with people's vulnerability. Thus, one should not confuse this variable as a measure of the perception of the state of natural resources in general. The composite variable includes observations about deterioration of the natural resource base, loss of biodiversity, deforestation, river erosion, increased salinity and siltation processes among others. 


\section{Share of vulnerability domains among small farmers}

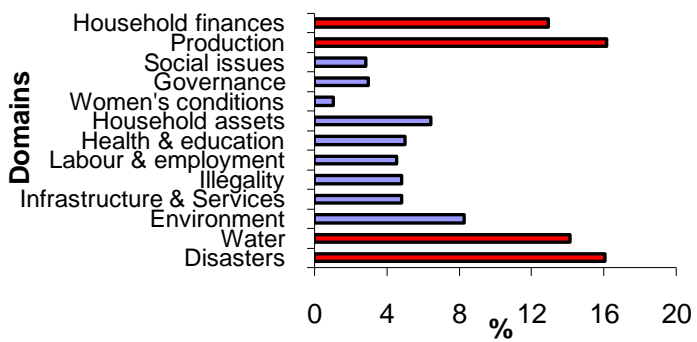

Share of vulnerability domains among rura wage labourers

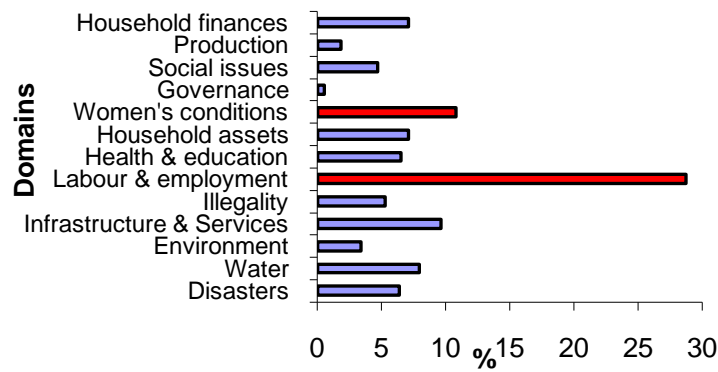

Share of vulnerability domains among artisanal fishers

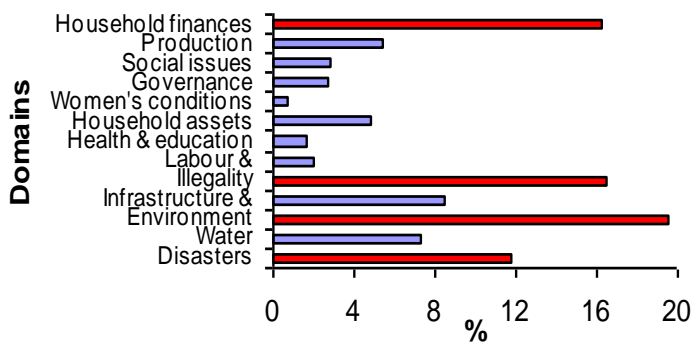

Share of vulnerability domains among urban wage labourers

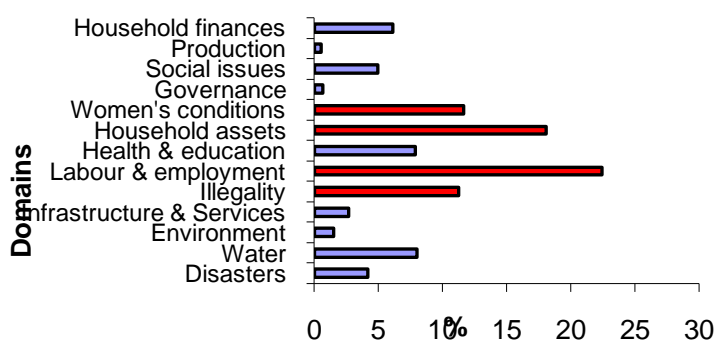

Figure 1:- Share of vulnerability domains by livelihood groups.

Directly linked to the environmental aspects of people's vulnerability are those processes that - for analytical clarity - we grouped under the heading disasters. These disasters are primarily climate change induced disasters and often demonstrated as climate variabilities. This composite variable summarizes the impact of tropical cyclone, tidal bore (due to tropical cyclones and also affected by sea level rises), drought, mud slides, as well as rat and insect attacks on crops and post-harvest resources. Comparatively, respondents perceived these disasters to be affecting small farmers and artisanal fishers more predominantly (respectively $39.1 \%$ and 30.3\%). While farmers and fishers are directly affected by adverse and changing weather conditions and vagaries, respondents saw disasters as affecting laborers less immediately but have a strong secondary impacts in a subsequent time period.

Employment issues received the highest scores overall. Respondents perceived that employment constitutes a dominant element in people's vulnerability among rural wage labour and urban wage labour (respectively scoring $50.1 \%$ and $39 \%$ of the responses), while less so for small farmers (8\%) and artisanal fishers $(3.5 \%)$. The variable labour and employment utilized here summarizes the lack of employment opportunities, the lack of clear labour policies, the low levels of wage rates, child labour as well as accidents on the job and the need to migrate in search for employment. Among all these aspects, the lack of employment opportunities accounts for $53.4 \%$ of the total responses, followed by the perceived low level of wage rates that scored $39.1 \%$.

Women's conditions are more prominently perceived as a cause of vulnerability in the employed labour sector. This is primarily a function of wage discrimination and the social division of labour that excludes women from many professions. Also, wage rates for female workers are generally lower than their corresponding male counterparts. Women's vulnerability is also exacerbated by violence, harassments and notion of insecurity both at home, private and public sphere. 
For artisanal fishers, illegality figures as a key cause of their vulnerability status. This clearly reflects the hocuspocus state of capture fisheries, the lack of regulatory frameworks for the sub-sector, the difficulties in implementing even the weak policies and legal frameworks, the fishers' total dependence on intermediaries for means of production, and their general subalternity vis-a-vis powerful boat-owners.

Results seem to suggest that for primary producers conversion of farm products into financial capital is difficult. Results from case studies, in fact, suggest that a large portion of the staple crops planted are utilized for own consumption. This leads to a dearth of liquidity circulation that affects household finances, as confirmed by the high incidence of monetary shortages as a cause of vulnerability among small farmers and artisanal fishers. In the variable household finances about $51.5 \%$ of the responses perceived lack of cash as a key determinant of people's vulnerability in the coastal zone. For farmers and fishers, this is exacerbated by a concomitant drop in their purchasing power and a steady rise in the cost of productive farming and fishing inputs. Interestingly, responses pertaining the other two groups (rural wage labour and urban wage labour) tended to give less importance to the availability of cash as a vulnerability factor (respectively 19.3\% for artisanal fishers, $16.2 \%$ for small farmers, 8.3 for rural wage labourers and $7.7 \%$ for urban wage labourers).

For small scale farmers and artisanal fishers, vulnerability is strongly correlated with the conditions underlying their livelihood activities (i.e. production). In particular, issues concerning farm input prices and difficulties accessing viable markets account for $67.2 \%$ of the responses obtained in the sample. Conversely, among urban wage labour and rural wage labour vulnerability is rather a function of their capacity to access labor markets, the stability of employment and the wage rates. As highlighted above, women in these groups are particularly vulnerable because of the discriminatory ideologies inscribed in the employment dynamics.

Illegality figures preponderantly as a cause of vulnerability among urban wage labour and fishers. Deteriorating law and order in combination with fraudulent behavior account respectively for 56\% and $18.4 \%$ of the composite variable illegality. For fishers, illegality constitutes a severe impediment to access natural resources while simultaneously reproducing the conditions for an unhealthy control of natural resources by powerful elites. For urban wage labour, illegality needs to be seen in close connection with housing problems (which accounts for a large share of the responses emerging in the graph under the heading household assets). Urban wage labours are mostly seasonal migrants for which securing housing is a severe problem. In fact, due to their powerlessness in negotiating, they often get entrenched in cycles of exploitation for obtaining miserable forms of housing. This in turn affects social order, their health, and reproduces cycles of exclusion and marginalization in urban areas.

Similarly, issues related to water are mostly perceived by respondents as affecting the vulnerability of small farmers, while less so for the other three groups. What needs to be pointed out here is the fact that the variable water includes observations about water management as well as information about the water conditions. In particular, the value of the variable in its contribution to vulnerability is driven by the respondents' emphasis placed on the difficulties in accessing safe and drinking water and the arsenic problem (roughly 61\%). In addition, water logging and drainage congestions are seen as particularly problematic.

Social issues were raised by respondents as factors affecting people's vulnerability status. These include observations on demographic elements (family size, polygamy, early marriages and child marriages); cultural elements (dowry, superstition) as well as social dysfunctions such as prostitution, personal insecurity, and harassment by powerful individuals and various forms of addiction. However, two variables account for a large portion of the total responses in the composite variable "social issues" - i.e. dowry (60.4\%) and large family size $(19.6 \%)$.

The low levels of the variable health and education need to be explained. This variable looks primarily at the human capital elements of health and education (e.g. skills, education, incidence of sickness, etc). However, respondents pointed out that the scarcity of educational and health facilities (respectively accounting for $30.5 \%$ and $35.1 \%$ of the variable infrastructure and services) contributes to people's vulnerability across the livelihood groups analyzed, though the issue seems to be particularly felt with regards to the small farmers.

Respondents saw the possession or control of household assets as an element of vulnerability affecting primarily urban wage labour. The high score obtained, however, is explained by the inclusion of observations about housing 
problems which concerns in large part only that group (88.5\%). If housing is extracted from the set of indicators composing the variable "household assets" then the issue of access to land, livestock, equipment and sanitation is more evenly spread across the four livelihood groups analyzed.

Livelihoods-vulnerability mapping: From the detailed data of the each district the study also created a spatial map identifying various vulnerability level for each of the four major livelihood groups. This was done for all nineteen coastal districts and then lumped together to portray the situation for the coastal zone in general. An upazila (and municipality for urban areas) wise identification strategy was adopted in understanding the distribution of various vulnerability factors within respective districts. Four livelihood-wise vulnerability maps at an upazila level were produced under the study.

The four maps illustrated (Figure 4 below) how vulnerability is widespread across the coastal zone. A distinction is made between the four livelihood groups using an innovative mapping methodology. What emerges from these maps is the fact that vulnerability has indeed a geographical element to it. For example, it is clear that for all four groups, the southwestern region is particularly subject to various types of composite vulnerabilities. The same is true for the Meghna estuary region and some of the exposed districts.

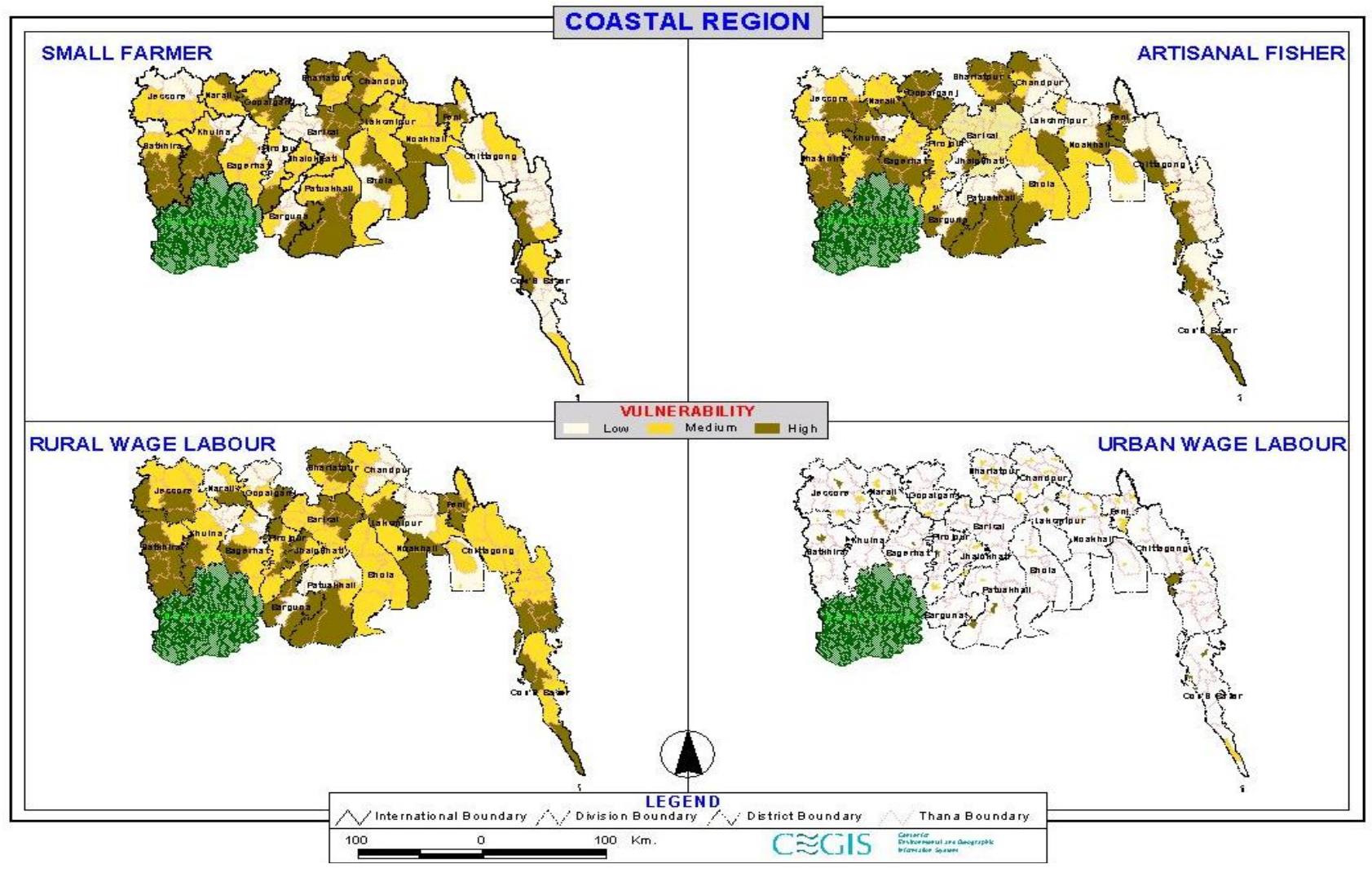

Figure 4:- Livelihood-wise spatial vulnerability maps of the coastal zone (Source: CEGIS: 2004).

Exogenous vs. endogenous nature of vulnerability: The nature of vulnerability factors identified in the study are then analyzed further considering the 'intrinsic characteristics' of the people or groups as well as considering the 'external factors'. The intrinsic vulnerability factorscan be termed as "endogenous" factors and the external factors can be termed as "exogenous factors". On an overall basis, it was found that a greater share of exogenous variables over the endogenous ones have emerged from the field data. This confirms the high level of exposure to various shocks in the coastal zone and across the major livelihood groups as well. 


\section{Nature of factors accounting for vulnerability}

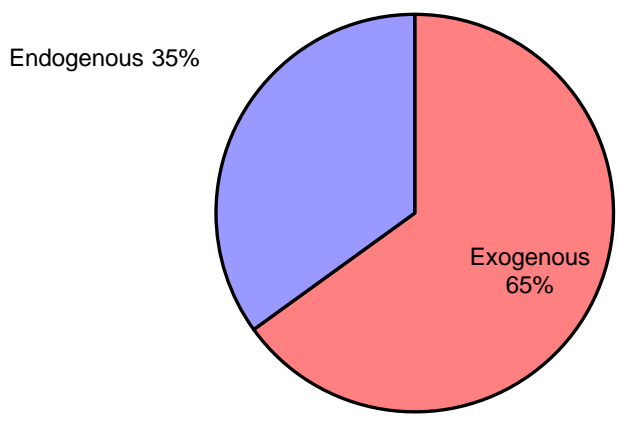

Figure 3:- Share of vulnerability factors by nature.

\section{Adaptive measures andstrategies:-}

As people in the coastal zone of Bangladesh remain vulnerable to various kinds of critical factors, they build their own adaptive strategies and mechanisms to deal with those. The confluence of these factors are necessitating action to proactively adapt natural, built, social, and economic systems in their own respective contexts. It was found that typologies of adaptation vis-a-vis adaptation measures are adopted by people in the coast ranging from anticipatory, concurrent, reactive or event through autonomously planned or from incremental or transformational measures. Individual, group, or community who remain successful in devising adaptive strategies to respective vulnerabilities gradually build 'interfaces of resilience'.Contrary, those who fail to build adequate adaptive strategies become transiently vulnerable to host of pressing factors.

The study showed that there are differences among the spheres where the adaptation mechanisms are enacted. Some mechanisms are directly enacted at the individual or household level. Such mechanisms are limiting food consumption, sell assets and so forth. On the other hand, adaptation mechanisms are also enacted at livelihood group level where people devise their strategies at more occupational and livelihood domain and scoping various options. People enact these strategies in a group manner and in some cases react according to their livelihood activities and needs.

For small farmers few such examples are adjustment of farming practices, raise sides of land and so forth. Similarly to avoid tropical cyclone induced vulnerabilities artisanal fishers rely on near shore fishing, fishing in groups etc. To adapt to seasonal shortage of labour, rural wage labourers often out-migrate to other places where work is available. However, beside the household and livelihoods level adaptation coastal people are also found devise their adaptive mechanisms at communityor ecological domains such as maintaining and protecting their ecological settings through protective embankments, social resolutions of eco-systemic conflicts between and so forth. However, it was found that many adaptation measures indicated from the coastal livelihood groups are of mixed nature ranging from spontaneous adaptation, measures taken by community as a whole, measures sought in collaborations with the external support such as structural measures identified to be implemented through the support of government departments and service provide and so forth. It was also found that a great deal of adaptation more recently are shaping up through the community-based adaptation measures involving adaptation and socio-economic development and even involving the disaster risk reduction measures together.

The table below outlines the most common adaptive mechanisms enacted by all the groups in respect to the specific vulnerabilities. Here the prominent adaptive mechanisms are listed for the major ten coastal vulnerabilities irrespective to livelihood groups. 
Table 2:-Adaptive mechanisms to major ten coastal vulnerabilities.

\begin{tabular}{|c|c|}
\hline Vulnerability factors & Adaptive mechanisms \\
\hline $\begin{array}{l}\text { Lack of employment } \\
\text { opportunities/ seasonal } \\
\text { employment }\end{array}$ & $\begin{array}{l}\text { Livestock rearing, loans/credits from NGOs, out migration, take up secondary } \\
\text { occupation, handicraft, Loan from local money lenders/ mahazan, change of } \\
\text { occupation, mortgage/ sell assets, Limit family consumption/ expenses etc. }\end{array}$ \\
\hline $\begin{array}{l}\text { Arsenic/ Lack of safe } \\
\text { drinking water }\end{array}$ & $\begin{array}{l}\text { DTW water, harvest rain water, boil pond water, drink surface water, local methods } \\
\text { (dug well, three pitcher method etc.), NGO support etc. }\end{array}$ \\
\hline Low wage rate & $\begin{array}{l}\text { Limit family consumption/ expenses, seek credit/ loan, mortgage/ sell assets, out- } \\
\text { migration, change occupation and so forth. }\end{array}$ \\
\hline ash/ savings & $\begin{array}{l}\text { Rely on dadon, seek credit/ loan, mortgage/ sell assets, rely on middlemen/ broker, } \\
\text { seek NGO support, seek support from the relatives, rear livestock, rely on homestead } \\
\text { gardening etc. }\end{array}$ \\
\hline d order & $\begin{array}{l}\text { Seek support from authority, rely on social resolution, stay united/ in groups, } \\
\text { maintain good relation with local influential people, take personal measure (self- } \\
\text { protection) etc. }\end{array}$ \\
\hline Cyclone/ tidal bore & $\begin{array}{l}\text { Take shelter in cyclone shelters, take shelter in safe locations, store food/ assets } \\
\text { under ground, shelter livestock in killa, wait for the signals, respond to signals, rely } \\
\text { on near shore fishing, untie livestock, cover tube wells, change occupation etc. }\end{array}$ \\
\hline Housing problems & $\begin{array}{l}\text { Floating night over, travel regularly from native villages, migrate out, slum dwelling, } \\
\text { share space etc. }\end{array}$ \\
\hline $\begin{array}{l}\text { of skills/ education/ } \\
\text { cal knowledge }\end{array}$ & $\begin{array}{l}\text { Work for low wage, take up inferior work, change occupation, work long hours, seek } \\
\text { Govt./NGO support, listen to radio/ TV/ Media, work for credit, food for work etc. }\end{array}$ \\
\hline Low female wage rate & $\begin{array}{l}\text { Work for low wage, take up inferior work, household work, work long hours, } \\
\text { handicraft, livestock rearing, homestead gardening etc. }\end{array}$ \\
\hline $\begin{array}{l}\text { Flood/ tidal flood/SLR/ } \\
\text { mud slide }\end{array}$ & $\begin{array}{l}\text { Raise protective embankments, shift to crops that grow in different seasons/ post } \\
\text { flood crops (e.g. Rabi crop, vegetables, cultivate local variety of rice that harvest in } \\
60 \text { days), remove drainage congestions etc. }\end{array}$ \\
\hline
\end{tabular}

\section{Gender-specific vulnerabilities and adaptive mechanisms:-}

Women are found as the most vulnerable in the coastal zone (Yasmeen, A and Murshid, S., 2004). Men's and women's priorities for adaptation are found to be shaped by the existing socio-cultural-religious norms, roles, and responsibilities and how strategies are developed through various prevailing discourses in the coast(Cannon, $\mathrm{T}$, 2002). From a gender analysis of vulnerability domains, it emerged that for women the critical factors are: women's living conditions, social-cultural issues, household assets, household finances, water, health and education, environment, governance, disasters, labour and employment and so forth. A more detailed caseexplored under the assessment on the gender differentiated vulnerabilities confirmed that women are doubly vulnerable to various contexts as they are also remain responsible for managing the household issues and dependent family members. Women are vulnerable to external factors and bear the load of the intra-household as well. Results pointed out the women's conditions, personal insecurities and social factors are also prominently make women vulnerable in the social order. Access to public services (e.g. healthcare services) are also creating a double vulnerability for female members across all the livelihoods groups in the coastal zone.

Beside the livelihoods-wise and vulnerability wise variations of adaptive strategies some gender specific adaptive mechanisms emerged. Women in the coastal zone are found to take various context-specific adaptive measures to various kind of vulnerabilities within the households and beyond. Within their households, to avoid food insecurity vulnerabilities relating to the consumption women were found more often adjust meals within households and consider activities that can avoid the immediate vulnerabilities for the households. The case study findings suggest that women members in different parts of the coastal zone were found involve with various kind of activities that can support the households in critical periods. Growing livestock (i.e. poultry, goat etc.), homestead gardening, cottage industries, minor financial savings so forth are amongst the major coping measures that women are seen taking. Men in contrast were found considering the extra-household or activities outside household coping measures against different kind of vulnerability factors. To cope with the vulnerabilities men often rely more on the external supports or means. Support from the money lenders (dadon/mohazon), adjustment/negotiation of the market prices in a united manner with other farmers of the grown products are examples that external coping strategies.Men and 
women of course often adopt some coping measures and build strategies with specific role to each other. One good example of it the case of women's labourers in the agricultural fields. To adapt to the labour crisis or to give away wage to other labourers women participate in on agricultural activities in the field. In crisis periods as well, both men and women jointly work and try to adapt to the situation. Both men and women were found seek support from the relatives and kin to avoid different vulnerability contexts.

\section{Reflections and validation through specific cases:-}

A number of case studies have been carried out to verify the representativeness and uniqueness of the vulnerabilities persist in the coastal zone of Bangladesh. The case study findings on one hand tested the representativeness of the district level findings and looked at the diversity and/ or uniqueness of various cases and groups on the other.

In this respect, the selection of the case study themes remained largely dependent upon the findings and results of the district round consultation sessions (e.g. Arsenic was selected because this was found as one of the most pronounced vulnerability factor in the coast). In selecting the case study locations geographical dispersion of the case studies also played a specific role. Case studies, therefore, provided some regional connotations (e.g. shrimp farming and salt farming case study) and vulnerabilities to special or isolated livelihoods (e.g. bawali - forest product-leaf collectors, mouwal -honey collectors) or isolated livelihoods of from remote islands such as ManpuraIsland etc. With specific interest to both thematic interest and with interest to location specific aspects of these case studies highlighted vulnerabilities from southwestern districts to southeastern coast of Bangladesh. Some of the key findings emerged from the case studies are as follows:

The general patterns that were found in the district level consultations were confirmed in the case studies. Several case studies confirmed both exogenous and endogenous types of vulnerabilities are composing the vulnerability of the groups. Environmental vulnerability factors are predominant among the primary producers (small farmers and artisanal fishers). It was found that most of the exogenous factors environmental factors and the endogenous factors are related to economic conditions. The case study on the shrimp farming and household budgeting pointed out the similar conclusions.

A case study on the food security situation in the southwestern coast (carried out in three upazilas of two districts of the southwestern zone) significantly highlighted the variations within the same livelihood group. Pointing out the case of food security of various types of farmers (i.e. two types of shrimp farmers and paddy farmers) the study highlights the intra group variation. However, in spite of the variations it seems that the major types of vulnerabilities are mostly relating to economic, environmental and governance factors specific to that particular region.

Two case studies one on the arsenic and the other on the shrimp farming highlighted the vulnerabilities relating to environmental or physical factors. However, the two case studies are more meaningfully dugout the important issue of lack of adequate policy to improve the conditions respectively of arsenic and salt farming. This signifies the earlier findings of the district round sessions where similar conclusions were emerged regarding policy and governance.

Some location specific vulnerabilities are highlighted in the case studies. Particularly, in the arsenic case study (lack of safe drinking water), in the gender differentiated vulnerability case study in Lakshimpur (river erosion) and in Manpura case study (isolation, cyclone, river erosion etc.) the location specific vulnerabilities are emerged.

Environmental factors with connotation to resource degradation coupled with governance factors are creating a major vulnerability for the minority livelihood groups. Particularly the case study on the bawali and mouwali livelihoods and the overall observation on the artisanal fishers in the coast suggest the same type of composition as a major pattern of vulnerability in the coast.

One of the significant findings came out of the case studies that for a continuing livelihoods people in the coastal zone are taking up a number of activities. It was found that most of the occupational groups in addition to their major livelihood activities are involved in multiple livelihood activities. Although some of the primary producing groups are relying heavily on their age old pattern of livelihoods but people do not hesitate to take up whatever livelihood opportunities their community, natural condition or the socio-economic conditions permit them to take. In 
this respect it can be suggested that the lack of livelihoods opportunities in many cases comprehend a better livelihoods for the poor in many parts of the coast.

In general in most of the case studies the economic factors are found as a premiere vulnerability among the coastal livelihoods. The household budgeting concentrated more into this and found that most of the households portray a deficit household budget (income-expenditure) and have to rely on coping mechanism that is largely based on societal conditions and relations.

The findings on the adaptive mechanisms are also found similar to the district level findings. Case studies at household level highlighted that coping mechanisms such as relying on borrowing informally (dadon/mohazon), micro-credit facilities based on NGO services are widely practiced. However, the dadon system differentially pointed out often as vulnerability factor and also pointed out as a coping to intense poverty. The policy recommendations relating to these informal but widely practiced systems were found as least articulated in many cases.

\section{Conclusions:-}

The vulnerability ofthe major livelihood groups in the coastal zone of Bangladesh depicted a multi-domain and uniquely situated contexts. High degree of exposure to natural disasters primarily amplified due to changing climate, social-ecological-cultural contexts of the local population, and difficulties in obtaining sufficient and stable incomes to respond to risk factors.

The assessment pointed out that the small farmers in the coastal zone face principally physical (natural), economic and financial vulnerabilities as they are more dependent on the land-based productive systems while the vulnerabilities for artisanal fishers are more of functions of continued exposure to physical and natural disasters due to changing climate. The changing climate is manifesting more frequent and more intense natural disasters in the Bay of Bengal $(\mathrm{BoB})$ which is a primary force of coastal and marine hazards of the coastal zone of Bangladesh. The condition of the urban and rural wage laborers suggested that these two groups are subject to the natural disasters but also severely impacted by the spiral effect of these to the overall coastal economy and thereby highly exposed to the economic constraints that prevent them from realizing the full potential of their livelihoods. In the urban areas, this situation is exacerbated by additional social-living condition related factors.

The assessment indicated that across all these four livelihood groups, vulnerabilities are rather perceived to be the function of 'exogenous factors' but due to 'endogenous characteristics'. Hence the vulnerability of the coastal livelihoods group are constructed through a combination of both exogenous factors more as a drivers and due to the impediments of endogenous factors that actually reduce the level of capacity to withstand those and even impede these groups to adapt to the current and future vulnerabilities to its needed level.

A major conclusion emerged from this livelihood-based social-ecological vulnerability study is that the vulnerabilities for each major livelihood groups varies both in nature and in intensity in the coast. The overriding chronic poverty situation has remained as a common barrier to build any strong resilience against exogenous forms of vulnerabilities. The vulnerabilities are largely mediated by multiple factors that fall into natural, economic, social and governance domains but each livelihood group has their own composition of vulnerability. Some of these are more prone to covariant ones while many are of idiosyncratic in nature. This finding calls for a policy implication that would compose of issues of reduction of livelihood group specific unique patterns of vulnerability as well as resilience against covariant or whole sell vulnerabilities that often caused factors such as natural disasters and so forth. Addressing the issues from a more inclusive manner incorporating gender, diversity and social inclusion issues are critical for future sustainability as well.

Prevailing nature of this vulnerability among the major coastal livelihood groups consequently calls for an integration of multiple domains and adoption of context-livelihoods-time specific development, resilience and adaptation strategies for future. The 'Coastal Zone Policy' (MOWR, 2005) and 'Coastal Development Strategy'(MOWR, 2006) adopting an integratedapproach seemingly have made some progress towards it but the pathway now leads towards a greater challenge of continuing an 'operational, effective and inclusive' Integrated Coastal Management (ICM) for Bangladesh reflecting unique dimensions of sustainable development and resilient the coastal zone in Bangladesh. 


\section{Acknowledgements:-}

The articleis developed from the findings of the study titled 'Vulnerability Analysis of the Major Livelihood Groups in the Coastal Zone of Bangladesh' which was supported by the collaborative support of the Food and Agriculture Organization of United Nations (FAO), Integrated Coastal Zone Management Program (ICZMP) Bangladesh and Center for Geographic and Environmental Services (CEGIS). The Authors acknowledges valuable contributions of all the researchers, study partners who were involved in various stages of the study including Fabio Pittaluga, Rob Kaudstaal, Md. Rezaur Rahman,Monirul Islam, Mosharref Hossain, Abu Saied Saiful Islam, MohammadRagib Ahsan, KaziKamrull Hassan and others who were involved in various stages of the study.

\section{References:-}

1. Baulch, B., Hoddinott, J., 2000. Economic Mobility and Poverty Dynamics in Developing Countries. Journal of Development Studies 36, 1-24.

2. BBS, 1992. Population Census 1991 (19 coastal districts from the district series). Bangladesh Bureau of Statistics. Dhaka, January 1991 and onward.

3. BBS, 1999. Census of Agriculture 1996. Bangladesh Bureau of Statistics. Dhaka, July 1999.

4. Cannon, T., 2002. Gender and climate hazards in Bangladesh.In Gender and Development, 10(2),

5. CEGIS, 2004.Vulnerability Analysis of Major Livelihood Groups in the Coastal Zone of Bangladesh. Dhaka, Bangladesh, May 2004.

6. Chambers, R., 1989. Editorial Introduction: Vulnerability, Coping and Policy. IDS Bulletin 20 (2): 1-7.

7. Dilley, M. and Boudreau, T.E., 2001.Coming to terms with vulnerability: A critique of the food security definition. Food Policy. 26:3, 229-247.

8. Maxwell, S., and Frankenberger, T.R., 1992.Household Food Security: Concepts, Indicators, Measurements. A Technical Review. UNICEF and IFAD. New York and Rome.

9. McCulloch and Callandrino, M., 2003.Vulnerability and chronic poverty in rural Sichuan. World Development, 31(3).

10. MoEF, 2008. Bangladesh Climate Change Strategy and Action Plan 2008. Ministry of Environment and Forests, Government of the People's Republic of Bangladesh, Dhaka, Bangladesh.

11. Moser, C. 1998. The Asset Vulnerability Framework: Reassessing Urban Poverty Reduction Strategies. World Development 26, 1, 1-19.

12. MOWR, 2005.National Coastal Zone Policy. Ministry of Water Resources, Government of Bangladesh.

13. MOWR, 2006.Coastal Development Strategy: Bangladesh. Ministry of Water Resources, Government of Bangladesh.

14. PDO-ICZMP, 2004. Living in the Coast: Problems, Opportunities \& Challenges. Program Development Office, Integrated Coastal Zone Management Plan Project. Dhaka. June 2004.

15. Sen, A., 1981. Poverty and Famines: an Essay on Entitlement and Deprivation. Clarendon Press. Oxford, U.K.

16. Swift, J. R., 1989. How Rural People are Vulnerable to Famine? IDS Bulletin 20 (2): 8-16.

17. Yasmeen, A and Murshid, S., 2004. Women of the Coast A Gender Status Paper on the Coastal Zone (WP 027), Program Development Office for Integrated Coastal Zone Management Plan Project; Bangladesh. Dhaka. 